\title{
Applying influence for systems change in a large-scale community-based prevention intervention
}

\author{
Monica Bensberga,b \\ a Our Health Inc., Melbourne, VIC, Australia \\ b Corresponding author: bensberg@bigpond.net.au
}

\section{Article history}

Publication date: June 2021

Citation: Bensberg M. Applying influence for systems change in a large-scale communitybased prevention intervention. Public Health Res Pract. 2020;31(2):e30122005. First published 22 April 2020. https://doi. org/10.17061/phrp30122005

\section{Key points}

- Within a systems approach to preventive health, practitioners who see themselves as part of the system that surrounds them can use their influence as a means of establishing health-promoting change

- Many health promotion practitioners need to build their capacity so they can employ 'self-in-the-system' tactics. This could help to shift their practical know-how from programmatic approaches based on individual projects towards more systemic ones

\section{Abstract}

Study objectives and importance: The study aimed to explore how a 'selfin-the-system' approach was understood and applied by Healthy Together Community (HTC) practitioners, as part of Healthy Together Victoria's (HTV) systems approach to community-level health promotion. Self-in-the-system tactics were a means of systems practice within HTV, where practitioners viewed their connections to others as parts of the systems that surround them. It enabled them to intervene via exerting influence, by drawing upon relationships to leverage what people can contribute to achieve change.

Study type and methods: This qualitative research included 31 primary semistructured interviews. The initial participants were identified using purposive sampling and subsequent participants were nominated via snowball recruitment. The interview questions focused on participants' understanding of systems thinking and about how it had been developed and applied in HTCs. The interviews were recorded and transcribed verbatim. Inductive thematic analysis was based on Braun and Clarke's six-phase analysis framework.

Results: The research findings show that some of the HTC practitioners viewed themselves as part of the prevention system and were able to draw upon their relationships to achieve change. They had invested time to develop trusted connections upon which to engage and encourage cooperation. The notion of a 'prevention change agent' developed, referring to practitioners who used their influence to achieve HTC goals. This practical know-how was developing in HTCs as people were able to describe the concept, rather than provide examples of working in this way.

Conclusion: Within a systems approach to community-level health promotion, a practitioner's capacity to identify their role in complex adaptive systems and their ability to influence others are potentially powerful skills to facilitate change. Self in the system is a developing skill for systems practice for prevention and it may add more systemic ways of working compared with traditional programmatic methods. 


\section{Introduction}

Systems thinking is tiptoeing its way into communitybased health promotion. 1,2 With it comes a new mindset for prevention, one that is holistic and accentuates the significance of connections between system parts and their interrelationships to a functioning whole. ${ }^{3}$ An aspect of systems thinking is practitioners' capacity to view their connections to and between others, as parts of the systems that surround them. ${ }^{4}$ This is known as 'self in the system', and its importance pertains to intervening via influence, where we draw upon our relationships to leverage what people can contribute to achieve change. ${ }^{5}$ Change is achieved by guiding population-level decisions towards a healthier status quo. ${ }^{6}$ The empowerment of others is vital as health promotion practitioners have very little, if any, positional power to improve the determinants of health. ${ }^{7}$ For that reason, self in the system is a competency that is framed alongside adaptive leadership skills - both require mobilising others, often without the authority of a leadership role. ${ }^{8,9}$

Healthy Together Victoria (HTV) was a large-scale Victorian State Government prevention initiative, which adopted systems thinking to reduce obesity and related preventable chronic disease from 2011 to 2016. The initiative used a complex, whole-of-system approach that required engaging community-level organisations via multifaceted and interconnected interventions ${ }^{10,11}$ to improve physical inactivity, poor diet, smoking and harmful alcohol use. ${ }^{12}$ Self in the system was a recommended means of systems change within HTV. The workforce members were described as 'change agents', working as self-aware change agents, with themselves as actors in the prevention system. ${ }^{13,14}$ Joyce et $\mathrm{al}^{15}$ described them as 'practice entrepreneurs', referring to a broader concept than that of a change agent, as these practice entrepreneurs were more adaptable and opportunistic in their work, in comparison to employing traditional methods of prevention. This was likely a consequence of HTV's broader systems-thinking methods. ${ }^{15}$ A key operating principle of these roles was that practitioners had influence beyond their positional power, and it was their responsibility to disrupt unhealthy systems. ${ }^{16}$ The change agents formed the Healthy Together Communities (HTCs) - community-based teams funded by HTV, which aimed to deliver chronic disease prevention interventions. The HTCs consisted of 12 teams, with 10-15 people in each HTC, based in local governments experiencing disadvantage. ${ }^{17}$

Encouraging a practitioner to perceive themself as a system participant can help them develop a mindset in which they consider their role in the complex set of circumstances in which they are embedded, and to subsequently see new opportunities to intervene. ${ }^{6}$ The instrument of change is mainly persuasive dialogue, using person-time-place interactions as disruptive events in the system. ${ }^{5}$ This is grounded in a practitioner's knowledge of complex adaptive systems and awareness of their structures, interdependencies, multiple perspectives and boundaries. ${ }^{18}$ As self-in-the-system tactics are in their infancy within systems approaches for health promotion practice, the research question that this paper aimed to advance was: how was self in the system understood and applied by HTC practitioners as part of HTV's systems approach to community-level prevention?

\section{Methods}

Research assumptions in this study were based on a social constructionist perspective, meaning that reality is perceived as being socially created between actors engaged in real-world circumstances. ${ }^{19}$ Qualitative methods were used to enable new ideas to emerge from the data via inductive analysis of the participants' comments regarding their ability to locate themselves within a human network (composed of relationships) and how they engaged with the network. ${ }^{20}$ To undertake thematic analysis, Braun and Clarke's phases ${ }^{21}$ were followed, mainly: reading and re-reading the data to be familiar with it; generating codes; searching for themes to identify meaning; refining themes; and determining the story of each theme and documenting it.

Thirty-one qualitative semistructured face-to-face interviews were conducted from May to July 2016. The selection criterion for participants was that they had held a role in influencing or implementing HTC's systems approach to health promotion for at least 10 months. Participants were drawn from stakeholder organisations such as the Victorian State Government's Department of Health and Human Services (DHHS), HTCs and the Centre of Excellence in Intervention and Prevention Science (CEIPS), which were responsible for HTC's workforce development and evaluation. The initial participants were identified using purposive sampling and subsequent participants were nominated via snowball recruitment. ${ }^{22}$ Interview participants included six from DHHS, three from the CEIPS and 22 from HTCs. Participants were initially contacted by telephone, followed with an email message containing written information. An interview guide was prepared and pretested. The interviews focused on participants' systemsthinking knowledge and about how it had been applied in HTCs. Questions included:

- What was your understanding of HTV's systems approach to prevention?

- Can you describe an example showing how you used systems thinking in practice?

The interviews were mostly conducted in participants' workplaces. Interviews ranged in duration from 23 to 120 minutes (average around 60 minutes). The interviews were recorded and transcribed verbatim. MB conducted the interviews and was unknown to the participants. Two researchers undertook the data coding. Data was analysed using Nvivo qualitative analysis software (Melbourne: QSR International; Version 12). Ethical 
approval for this research was obtained from the Human Ethics Advisory Group, Deakin University (HEAG-H 142 2015).

\section{Results}

The key themes derived from the interview findings are outlined below.

\section{Self in the system within a systems approach}

When asked about the application of systems thinking for prevention within HTCs, many participants discussed the Foresight Obesity System Map ${ }^{23}$ or recounted a definition of what constitutes a system. In contrast, a small number of people had a different understanding and spoke about a new way of working, from within the prevention system. These practitioners were interested in trying to understand the system's form that surrounded them, how it was functioning and how they thought that they could individually affect it. They were more likely to initiate change via influence compared with those practitioners who perceived themselves as separate from the system.

"Systems thinking means that everyone is a part of a broader system and everyone has the capacity to make shifts within the system." (HTC Team Leader, P15)

These practitioners valued the connections between themselves and others, they were conscious of being a part of the HTV system and considered themselves as a source of change from within it. However, only small number of HTC practitioners specifically talked about self in the system.

\section{Influence}

\section{Influence is relationship dependent}

Practitioners who viewed the prevention system as being made up of interactions among people, valued their relationships. For example, one participant acknowledged the connections that she had established and believed that they were robust relationships.

"I had a pretty good handle on relationships and their importance. We were really strongly connected. That permeates and impacts across the system." (HTC Evaluator, P18)

Another participant described how social connections were a prerequisite for getting things done. That is, relationships must be established first, before they could be called upon. They considered that relationships formed the foundation of personal agency.

"You have to look at your relationships locally. They are your currency to get things done. What's your bank account like? If you have a cold bank account in terms of relationships, you're not going to get this work done." (HTC Coordinator, P8)
Some participants described planning processes they had participated in to map key stakeholders in prevention systems. These meetings took place early in the establishment of the HTCs to acknowledge peoples' existing contacts as well as identify new relationships that ought to be established.

"We did a lot of relationship mapping and trying to work out who were the people that we needed to engage with." (HTC Coordinator, P7)

Participants were eager to expand their professional networks, however they did not appear to act on the mapping and specifically target individuals with the authority to achieve defined outcomes.

Gaining the trust of local stakeholders was an essential ingredient of effective implementation processes. Participants described a number of elements in building relationships that were built on trust. These included that building these relationships was an intensive and time-consuming process. Participants also commented that even when relationships were developed, they could not be taken for granted.

"Trust plays a huge part in this and yet it is so fragile." (HTC Coordinator, P8)

Participants discussed the need for enduring relationships when practitioners were required to work together for many years. They explained how a small conflict could permanently alter peoples' willingness to engage.

\section{Influence requires cooperation}

HTC practitioners held a common understanding that they would need to link to people with authority in order to achieve goals, even though a clear description of how to apply influence to achieve change wasn't provided by HTV. One participant expressed this as:

"We are talking about systems change, individual people are instrumental in that, the individual key decision makers and influencers. It really comes down to getting those individuals to engage." (HTC Team Leader, P15)

Although relationships were seen as the foundation upon which personal agency was based, some practitioners held a deeper insight about what was required. They were considering which individuals might have a stake in their work, how they operated and how to empower them.

"It's about understanding how other people operate within the system. Understanding who is connected to who. Who are the movers and shakers that are willing to help you with what you are doing?" (HTC Officer, P22)

A key message from HTV to HTC practitioners was that they had authority that extended past their positional power. Opportunities to instigate change in this way were described by a senior stakeholder as: 
"With systems, you've got influence far beyond where you think you have. Through your networks. You do ' $x$ ', the contacts you have got will do ' $y$ ', someone will do ' $z$ ', and then 'a' happens that you never envisaged would happen. But if you only do what you think you can do then all that will change is what you have got control over, which is 'bugger all' in terms of public health. People begin to broaden their horizons when they realise that they have influence." (CEIPS, P2)

Prior to HTV, most HTC practitioners were not familiar with achieving change through direct and indirect contacts. It was a novel skill for them. Fewer practitioners had managed to act upon their contacts to achieve health-promoting changes, although they had considered who the champions and influencers were and the possibility of engaging with them. It appears that the 'who' of self in the system had been discussed, without the 'how'. The influence that others held was noted, yet how it could be harnessed to achieve HTC purposes did not seem to have been considered. This was demonstrated when an HTC practitioner could define the process for change - for example Person A influences Person B to influence Person $\mathrm{C}$ - but was not able to describe having implemented it.

"How do you [Person A] influence them [Person $B]$ ? How do you get to them? The next step of that is, who do they then influence [Person C]? Do they have networks that I don't have?" (HTC Team Leader, P15)

\section{Context}

\section{System impacts}

The prevention system exerted pressure upon the people within it, and the people can also have an impact on the system itself. One participant was alert to these system effects and summarised it as:

"It is about inquiring about yourself and the way you're working and how this impacts on the system, and how the system impacts on you." (HTC Evaluator, P18)

Two HTC practitioners talked about how they perceived that the new HTV prevention system had exerted influence on them. One participant provided an example of the pressure that she had experienced having to implement HTV's policy direction of a systems approach to prevention, when colleagues were not supportive of this alternative way of working. Another example of a system impact on practitioners was the introduction of HTV's performance targets. This was a new model of government funding and agency accountability for health promotion, and a practitioner described it as stressful to attain the targets and to report on them to the DHHS. Other practitioners found HTV's systems thinking approach and reporting requirements to be challenging, but they had not viewed them as systemic work influences.

\section{System change agents}

A message from HTV to the HTC practitioners was that they were to achieve change via influence, and this was sometimes referred to as working as change agents. One participant compared the HTC practitioners' role to that of a secret informer with respect to accessing other peoples' authority:
"You operate like an ASIO agent, in that you're grooming other people, all those important people in your organisation that have access to influence and leverage within the community and system.
They are really operatives for health, not health promotion practitioners." (Government Policy Advisor, P1)

Change agents were given the task of expanding their stakeholder connections by building relationships. The purpose of the relationships was to enable change via cooperation with people who had the necessary power to achieve HTC goals. For example, this could entail connecting with council mayors and business leaders. A change agent was also referred to as a system facilitator and working with:

"... the key leverage points within the system. Our role is to navigate through the system and try to influence different people." (HTC Officer, P26)

Participants did not describe situations where they had deliberately persuaded people.

\section{Discussion}

Some of the HTC practitioners viewed themselves as part of the prevention system and were able to draw upon their relationships to achieve change. They had invested time to develop trusted connections, upon which to engage and cooperate. The notion of a prevention change agent developed; it referred to practitioners using their influence to achieve HTC goals. This practical knowhow was emerging in HTCs, as people were more able to describe the concept, rather than examples of working as a change agent.

This gap between the theory and practice may have been due to there being insufficient time to build the prevention workforce capacity from initially being inexperienced systems thinkers to applying self in the system. Other factors that may have limited its execution could have been the organisational constraints of local governments, such as centralised leadership or riskaverse culture. Additionally, the HTC practitioners may not have had agency to work this way. They may not have developed a systems mindset, that is, their ability to recognise system structures, their parts, interconnections and boundaries. ${ }^{18}$ Practitioners without a systems mindset 
will not have the foundation concepts of systems thinking to grasp the concept of self in the system. ${ }^{24}$

Despite the importance of relationship building, HTC practitioners were left to their own devices as limited guidance was provided by HTV. Furthermore, participants did not distinguish between the different types of relationships that were needed for different purposes, such as collaborating compared to empowering. Health promoters are typically familiar with collaborating. ${ }^{8}$ Collaborations are important for systems thinking for prevention, for example the long-standing partnerships that are needed to achieve the collective impact of multiple stakeholders coming together around a common challenge. ${ }^{25}$ In comparison, change agents' relations are established to motivate action and they may be shorter term and with people outside of those contacts already known to the practitioners. ${ }^{26}$ The goal of the change agent is rapid empowerment to influence, however the goal of the collaborator is cooperation for continuing partnerships. ${ }^{27}$ Perhaps HTC practitioners needed to learn how to engage in different ways to attain various end points.

Literature in this field highlights that conversations create the system's interconnectedness ${ }^{28}$ and health promotion practitioners capitalise on this by developing strong networks and bridging unseen connections through establishing relationships with other people who make up the system. ${ }^{29}$ They empower others by deliberately gaining trust and sharing information with innovators who take up new ideas and make them mainstream. ${ }^{8}$ HTC practitioners were moving towards these tactics, however they required capacity building to make self in the system a more readily accessible systems-thinking skill. For example, training in the advanced practice of 'reflection in action' could have increased their knowledge and enabled them to adjust their performance in the moment to drive change as it arises, thereby subverting the system in real time to attain their own goal. It is a reflective skill that involves adapting our actions to changing circumstances while they are occurring and being aware of the effects of our actions on the new situation. ${ }^{5,30}$

Overall, the study depicted that only some practitioners perceived themselves as part of the whole and had an understanding of self in the system as a means of initiating health-promoting change. These people were aware that persuading others was dependent upon trusted relationships within local networks. The cooperation of decision makers and influencers was also required. Participants acknowledged that the HTV context exerted pressure on their roles as change agents when trying to create useful stakeholder connections. The HTC workforce was more familiar with the notion of a systems facilitator than they were with its practice.

This study adds to the limited research that is available about the real-world use of system sciences in health promotion. ${ }^{15}$ The current research emphasis is largely methods based, such as causal loop diagrams and social network analysis. ${ }^{1,2,31}$ In contrast, this paper considers one skill (of a suite, e.g. exploring multiple perspectives, maintaining boundaries, identifying feedback loops) that is relevant to health promotion practitioners who are trying to solve complex public health problems. ${ }^{32}$ A limitation of this paper is the narrow focus on self in the system. Nonetheless, this focus appears to be unique within the health promotion literature.

Considering the impact that researchers can have on the collection of qualitative data, the researchers viewed themselves as actors within the prevention system and therefore took steps to mitigate possible impacts by participating in training in conducting interviews, developing and implementing interview protocols and scripts, and having two researchers concur on the data coding.

\section{Conclusion}

Within a systems approach to health promotion, the practitioner's capacities to identify their role in complex adaptive systems and their abilities to act upon others who have influence are pathways to faciltate change. Self in the system is a developing skill for systems practice for preventive health and it may aid in expanding traditional programmatic ways of working to more systemic ones. Health promotion practitioners require support in expanding their contacts and making new connections for the purpose of gaining support and cooperation. They need to understand what it means to be an active participant in the system, so that they are alert to shifts in their surroundings and able to lead any emerging trends. This is one method of systems practice that will equip them with contemporary skills to tackle enduring problems at the community level. Future research is needed into effective ways to embed self in the system within the day-to-day choices of strategies for use by health promotion practitioners.

\section{Acknowledgements}

Thanks to the people who participated in this research and to Professor Steven Allender and Associate Professor Gary Sacks, of Deakin University's Global Obesity Centre, for assisting with this study.

\section{Peer review and provenance}

Externally peer reviewed, not commissioned.

\section{Conflicts of interest}

$\mathrm{MB}$ was an employee of the DHHS during this research. The views in this paper do not necessarily represent those of the DHHS. 


\section{Author contributions}

$\mathrm{MB}$ is the sole author.

\section{References}

1. Allender S, Owen B, Kuhlberg J, Lowe J, NagorckaSmith $\mathrm{P}$, Whelan J, et al. A community based systems diagram of obesity causes. PLoS One. 2015;10(7):e0129683.

2. Brennan L, Sabounchi N, Kemner A, Hovmand P. Systems thinking in 49 communities related to healthy eating, active living and childhood obesity. J Public Health Manag Pract. 2015;S55-69.

3. Mabry P, Olster D, Morgan G, Abrams D. Interdisciplinarity and systems science to improve population health. Am J Prev Med. 2008;35(2S):S211-24

4. Abercrombie R, Boswell K, Thomasoo R. Thinking big: how to use theory of change for systems change. UK: NPC; 2018 [cited 2019 Jul 6]. Available from: www. thinknpc.org/resource-hub/thinking-big-how-to-usetheory-of-change-for-systems-change/

5. Hämäläinen R, Jones R, Saarinen E. Being better better: living with systems intelligence. Helsinki: Aalto University; 2014 [cited 2019 Jul 6]. Available from: sal.aalto.fi/ publications/pdf-files/being_better_better_living_with_ systems_intelligence.pdf

6. Behrens T, Foster-Fishman P. Developing operating principles for systems change. Am J Community Psychol. 2007;39:411-14.

7. Bensberg M. Initiating conversations that count. Melbourne: Our Health Inc.; 2018 [cited 2019 Jul 6]. Available from: drive.google.com/file/d/1Cc91vJOYh6eJM vfRP4GQBffpjR3m5hqD/view

8. Auspos P, Cabaj M. Complexity and community change. Washington: The Aspen Institute; 2014 [cited 2019 Jul 6]. Available from: assets.aspeninstitute.org/content/uploads/ files/content/docs/pubs/Complexity_and_Community_ Change.pdf

9. Bevan $\mathrm{H}$, Fairman $\mathrm{S}$. The new era of thinking and practice in change and transformation: a call to action for leaders. UK: NHS Improving Quality; 2016 [cited 2019 Jul 6]. Available from: www.england.nhs.uk/improvement-hub/ wp-content/uploads/sites/44/2018/09/Change-andTransformation-White-Paper.pdf

10. Strugnell C, Millar L, Churchill A, Jacka F, Bell C, Malakellis $\mathrm{M}$, et al. Healthy Together Victoria and childhood obesity - a methodology for measuring changes in childhood obesity in response to a community-based, whole of system randomized control trial. Arch Public Health. 2016;74:16.

11. Swinburn B, Wood A. Progress on obesity prevention over 20 years in Australia and New Zealand. Obes Rev. 2013;14(Suppl. 2):60-8.
12. Victorian State Government. Healthy Together Victoria frequently asked questions. Melbourne: Victorian State Government; 2013 [cited 2019 Jul 6]. Available from: www2.health.vic.gov.au/about/publications/ policiesandguidelines/Healthy-Together-VictoriaFrequently-asked-questions-FAQs

13. Department of Health. Prevention community model: standards and guidelines. Melbourne: Victorian State Government; 2012 [cited 2020 Apr 9]. Available from: www2.health.vic.gov.au/about/publications/ policiesandguidelines/Prevention-Community-ModelStandards-and-Guidelines

14. Healthy Together Victoria. Thinking systems guidelines (Draft). Melbourne: Victorian State Government; 2013. Copy available from author.

15. Joyce A, Green C, Carey G, Malbon E. The 'practice entrepreneur' - an Australian case study of a systems thinking inspired health promotion initiative. Health Promot Int. 2018;33:589-99.

16. Healthy Together Victoria. Strengthening Victoria's prevention system. Melbourne: Victorian State Government; 2009 [cited 2019 Jul 6]. Available from: www2.health.vic.gov.au/about/publications/ researchandreports/Strengthening-Victorias-preventionsystem

17. Roberto C, Swinburn B, Hawkes C, Huang T, Costa S, Ashe $\mathrm{M}$, et al. Patchy progress on obesity prevention: emerging examples, entrenched barriers, and new thinking. Lancet. 2015;385(9985):2400-9.

18. Williams B, Hummelbrunner R. Systems concepts in action - a practitioner's toolkit. California: Stanford Business Books; 2009. p. 3.

19. Patton M. Qualitative research and evaluation methods California: Sage Publications; 2015. p. 123.

20. Davidson S, Morgan M. Systems change framework. Sydney: Sax Institute, 2018 [cited 2019 Jul 6]. Available from: preventioncentre.org.au/wp-content/ uploads/2015/01/Systems-Change-Overview-w-Practices. pdf

21. Braun V, Clarke V. Using thematic analysis in psychology. Qual Res Psychol. 2006;3:77-101.

22. Liamputtong P. Qualitative research methods. Fourth edition. Australia: Oxford University Press; 2013. p. 85.

23. Government Office for Science. Foresight. Tackling obesities: future choices - obesity system atlas. London: Department of Innovation Universities and Skills; 2007 [cited 2020 Apr 10]. p. 4. Available from: assets. publishing.service.gov.uk/government/uploads/system/ uploads/attachment_data/file/295153/07-1177-obesitysystem-atlas.pdf

24. Armson R. Growing wings on the way: systems thinking for messy situations. UK: Triarchy Press; 2011.

25. Birney A. Cultivating system change: a practitioner's companion. Oxford: Do Sustainability; 2014. 
26. Acaroglu L. Disruptive design. New York: Disrupt Design; 2017. p. 73.

27. IPAA Victoria. Stakeholder engagement. Melbourne: Institute of Public Administration Australia; 2017.

28. Gladwell M. The tipping point: how little things can make a big difference. UK: Little Brown Book Group; 2014.

29. Kania J, Kramer M, Senge P. The water of systems change. Boston: FSG; 2018 [cited 2019 Jul 6]. Available from: www.fsg.org/publications/water_of_systems_ change

30. Meadows D. Thinking in systems, a primer. UK: Earthscan; 2008.
31. Rusoja E, Haynie D, Sievers J, Mustafee N, Nelson F, Reynolds M, et al. Thinking about complexity in health: a systematic review of the key systems thinking and complexity ideas in health. J Eval Clin Pract. 2018;24(3):600-6.

32. Arnold R, Wade J. A complete set of systems thinking skills. In: Proceedings of the Annual INCOSE International Symposium; 2017 July 15-20; Adelaide, Australia [cited 2019 Jul 6]. Available from: www.researchgate. net/publication/320246371_A_COMPLETE_SET_OF_ SYSTEMS_THINKING_SKILLS 